\author{
๑ Д. М. Железов \\ Одесъкий національний медичний університет
}

\title{
АНОМАЛЬНА ПЛАЦЕНТАЦІЯ У ВАГІТНИХ ІЗ РУБЦЕМ НА МАТЦІ
}

Мета дослідження - оцінка частоти аномальної плацентації у вагітних із рубцем на матці.

Матеріали та методи. Дослідження виконано на базі Одеського обласного перинатального центру впродовж 2016-2020 рр. Обстежено 435 жінок із рубцем на матці, в тому числі $118(27,1 \%)$ - із двома та більше рубцями. Середній вік обстежених склав $(33,3 \pm 1,2)$ року. Аналізували частоту виявлення аномалій плацентації на пренатальному етапі. Всім пацієнткам під час вагітності у термін 20 тижнів було проведено трансвагінальне ультразвукове дослідження за допомогою сканера експертного класу Accuvix V20 Prestige (Samsung Medison, Республіка Корея). Додатково проводили доплерометричне дослідження кровотоку по маткових артеріях. Статистичний аналіз проводили з використанням програмного забезпечення Statistica 13.0 (ТІВСО, США).

Результати дослідження та їх обговорення. У всіх обстежених вагітних із часу виконання оперативного втручання минуло більше 2 років. Рубець після консервативної міомектомії (KME) був у $109(25,1 \%)$ жінок. Середній термін після виконання КМ Е склав $(2,7 \pm 0,2)$ року. Найбільш часто реєструвалися фундальні $(28$, або $25,7 \%)$ та корпоральні $(73$, або $66,9 \%)$ розрізи. Частим явищем були аномалії прикріплення плаценти - у 70,3 \%, причому в структурі ураження переважало низьке розташування плаценти - 163 випадки, або 53,3 \%. Placenta accrete зареєстрована у 131, або 42,8 \%. Казуїстикою були випадки placenta increta (2,6 \%) та placenta previa (1,3\%). При оцінці частоти ускладнень у жінок із рубцем на матці встановлено, що у першому триместрі вагітності загроза переривання вагітності виникала у 20,4 \% вагітних, ранній гестоз - у 50,3 \%, анемія вагітних - у 64,1 \%. Затримку росту плода реєстрували у 69,6 \% вагітних. У третьому триместрі прояви диссункції плаценти реєстрували у 72,1 \%, прееклампсії - у 66,8 \%, анемії вагітних - у 73,6 \%. За літературними даними, поширеність аналогічних ускладнень у жінок без носійства рубця є втричі меншою. У 103 (25,9 \%) жінок вдавалися до оперативного розродження, в решти пологи відбулися per via naturales.

Висновки. Найчастішою причиною утворення рубця на матці $€$ KP $(74,9$ \%). Рубець після консервативної міомектомії був у 109 (25,1 \%) жінок. Середній термін після виконання КМЕ склав $(2,7 \pm 0,2)$ року. На відміну від жінок після КР, у яких розріз завжди локалізувався у нижньому сегменті матки, у пацієнток із рубцем на матці після КМЕ його локалізація відповідала первинній локалізації видаленого міоматозного вузла. Найбільш часто реєстрували фундальні $(28$, або 25,7 \%) та корпоральні (73, або 66,9 \%) розрізи. Частим явищем були аномалії прикріплення плаценти - у 70,3 \% жінок, причому в структурі ураження переважало низьке розташування плаценти - 163 (53,3 \%). Placenta accrete зареєстрована у 42,8 \% вагітних, placenta increta - у 2,6 \% та placenta previa - у 1,3\%.

Ключові слова: рубець на матці; плацентація; діагностика; прогнозування.

\section{АНОМАЛЬНАЯ ПЛАЦЕНТАЦИЯ У БЕРЕМЕННЫХ С РУБЦОМ НА МАТКЕ}

Цель исследования - оценка частоты аномальной плацентации у беременных с рубцом на матке.

Материалы и методы. Исследование выполнено на базе Одесского областного перинатального центра в течение 2016-2020 гг. Обследовано 435 женщин с рубцом на матке, в том числе 118 (27,1 \%) - с двумя и более рубцами. Средний возраст обследованных составил $(33,3 \pm 1,2)$ года. Анализировали частоту выявления аномалий плацентации на пренатальном этапе. Всем пациенткам во время беременности в сроке 20 недель было проведено трансвагинальное ультразвуковое исследование с помощью сканера экспертного класса Accuvix V20 Prestige (Samsung Medison, Южная Корея). Дополнительно проводили допплерометрическое исследование кровотока по маточным артериям. Статистический анализ проводили с использованием программного обеспечения Statistica 13.0 (TIBCO, США).

Результаты исследования и их обсуждение. У всех обследованных беременных с момента выполнения оперативного вмешательства прошло более 2 лет. Рубец после консервативной миомэктомии (КМЭ) был у 109 (25,1 \%) женщин. Средний срок после выполнения КМЭ составил $(2,7 \pm 0,2)$ года. Наиболее часто регистрировались фундальные $(28$, или $25,7 \%$ и и корпоральные (73, или 66,9 \%) разрезы. Частым явлением были аномалии прикрепления плаценты - у 70,3 \%, причем в структуре поражения преобладало низкое расположение плаценты - 163 случая, или 53,3 \%. Placenta accrete зарегистрирована в 131, или 42,8 \%. Казуистикой были случаи placenta increta (2,6 \%) и placenta previa (1,3 \%). При оценке частоты осложнений у женщин с рубцом на матке установлено, что в первом триместре беременности угроза прерывания беременности возникала у 20,4 \% беременных, ранний гестоз - у 50,3 \%, анемия беременных - у 64,1 \%. 3адержка роста плода регистрировалась у 69,6 \% беременных. В третьем триместре проявления диссрункции плаценты регистрировались у 72,1 \%, преэклампсии - у 66,8 \%, анемии беременных - у 73,6 \%. По литературным данным, распространенность аналогичных осложнений у женщин без носительства рубца втрое меньше. У 103 (25,9 \%) женщин прибегали к оперативному родоразрешению, у остальных роды произошли per via naturales.

Выводы. Наиболее частой причиной образования рубца на матке является КС (74,9 \%). Рубец после консервативной миомэктомии был у 109 (25,1 \%) женщин. Средний срок после выполнения КМЭ составил $(2,7 \pm 0,2)$ года. В отличие от женщин после КС, у которых разрез всегда локализовался в нижнем сегменте матки, у пациенток с рубцом на матке после КМЭ его локализация отвечала первичной локализации удаленного миоматозного узла. Наиболее часто регистрировались фундальные $(28$, или $25,7 \%)$ и корпоральные (73, или $66,9 \%)$ разрезы. Частым явлением были аномалии прикрепления плаценты - в 70,3 \% женщин, причем в структуре поражения преобладало низкое расположение плаценты - 163 (53,3 \%). Placenta accrete зарегистрирована у 42,8 \% беременных, placenta increta - в 2,6 \% и placenta previa - в 1,3\%. 
Ключевые слова: рубец на матке; плацентация; диагностика; прогнозирование.

\section{ABNORMAL PLACENTATION IN PREGNANT WOMEN WITH A SCAR ON THE UTERUS}

The aim of the study - to assess the frequency of abnormal placentation in pregnant women with a scar on the uterus.

Materials and Methods. The study was performed on the basis of the Odesa Regional Perinatal Center during 2016-2020. 435 women with a scar on the uterus were examined, including $118(27.1 \%)$ - with two or more scars. The average age of the patients was (33.3-1.2) years. The frequency of detection of placental abnormalities at the prenatal stage was analyzed. All patients during the 20-week pregnancy period underwent a transvaginal ultrasound examination using an Accuvix V20 Prestige expertclass scanner (Samsung Medison, Republic of Korea). Additionally, a Doppler study of blood flow through the uterine arteries was performed. Statistical analysis was performed using Statistica 13.0 software (TIBCO, USA).

Results and Discussion. In all examined pregnant women more than 2 years passed since the operation. Scar after conservative myomectomy was in 109 (25.1\%) women. The average term after CME was (2.7 \pm 0.2$)$ years. Fundamental (28 or $25.7 \%)$ and corporal (73 or $66.9 \%)$ incisions were most often registered. Anomalies of placental attachment were a frequent phenomenon - in $70.3 \%$, with a low location of the placenta in the structure of the lesion - 163 cases or $53.3 \%$. Placenta accrete was registered in 131 or $42.8 \%$. The cases of placenta increta (2.6\%) and placenta previa (1.3\%) were casuistic. When assessing the frequency of complications in women with a scar on the uterus, it was found that in the first trimester of pregnancy the threat of abortion occurred in $20.4 \%$ of pregnant women, early preeclampsia - in $50.3 \%$, anemia in pregnant women - in $64.1 \%$. Fetal growth retardation was registered in $69.6 \%$ of pregnant women. In the third trimester, manifestations of placental dysfunction were registered in $72.1 \%$, preeclampsia - in $66.8 \%$, anemia of pregnant women - in $73.6 \%$. According to the literature, the prevalence of similar complications in women without scarring is three times lower. 103 (25.9\%) women underwent operative delivery, the rest gave birth per via naturales.

The most common cause of scarring on the uterus is CS (74.9\%). Scar after conservative myomectomy (CME) was in 109 (25.1\%) women. The average term after CME was (2.7 \pm 0.2$)$ years. In contrast to women after CS, in whom the incision was always localized in the lower segment of the uterus, in patients with a scar on the uterus after CME, its location corresponded to the primary location of the removed myoma. Fundamental (28 or $25.7 \%$ ) and corporal (73 or $66.9 \%$ ) incisions were most often registered. Anomalies of placental attachment were a frequent phenomenon in $70.3 \%$ of women, with a low location of the placenta in the structure of the lesion - 163 (53.3\%). Placenta accrete was registered in $42.8 \%$ of pregnant women, placenta increta in $2.6 \%$ and placenta previa in $1.3 \%$.

Key words: uterine scar; placentation; diagnosis; prognosis.

ВСтУп. Однією з найбільш складних для диспансерного спостереження груп вагітних є жінки після перенесених оперативних втручань на матці. Показаннями до цих втручань $€$ як різноманітні патологічні стани, так і потреба в оперативному розродженні $[1,2]$. Рубець на матці може утворитися після кесаревого розтину (в нижньому матковому сегменті, корпоральний рубець на матці), після консервативної міомектомії до і під час вагітності (як без відкриття порожнини матки, так і з відкриттям порожнини матки). Рубець на матці може бути вислідом перфорації матки при внутрішньоматкових втручаннях - абортах, гістероскопії, а також при інших травматичних ускладненнях. Описано також рубці на матці після ектопічної вагітності (в інтерстиціальному відділі маткової труби, в місці з'єднання рудиментного рогу матки з основною по- рожниною матки, в шийці матки після видалення шийкової вагітності). Зрештою, рубець на матці може утворитися після реконструктивно-пластичних операцій (операція Штрасмана, видалення рудиментного рогу матки тощо). В усіх цих випадках збільшуються ризики аномальної плацентації та зумовлених нею ускладнень.

Традиційно, залежно від глибини проникнення хоріальних ворсин до міометрія, виділяють такі види аномальної плацентації - placenta accreta (поверхнева інвазія), placenta increta (глибока інвазія) та placenta percreta (тотальна інвазія, рис. 1).

Placenta increta $€$ ускладненням вагітності, яке характеризується повним або частковим дефектом децидуальної оболонки і неповним розвитком фріброзного шару, що призводить до аномальної інвазивної імплантації пла-

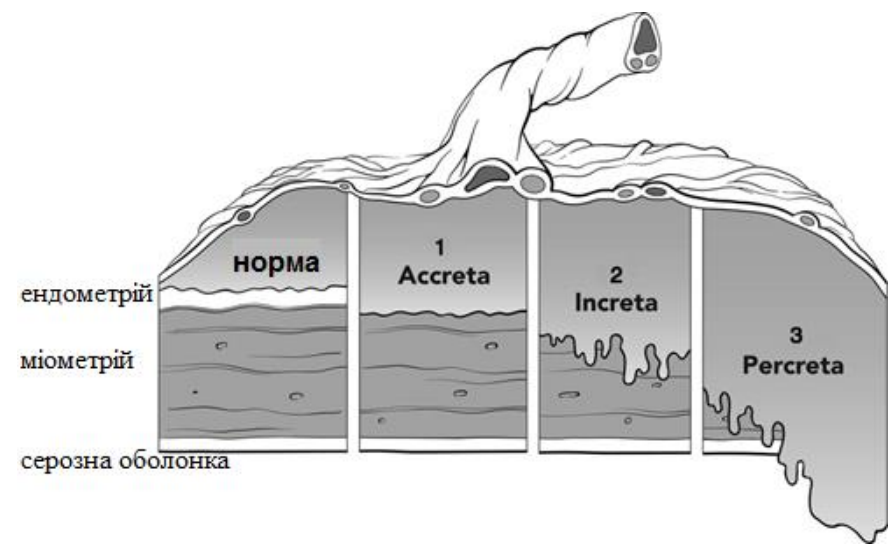

Рис. 1. Види аномальної плацентації. 
центи. Частота цього ускладнення складає 1 випадок на 2 500-7 000 пологів і збільшується у вагітних із рубцем на матці. За даними літератури, placenta increta пов'язана з ризиком масивної кровотечі, розриву матки й інорікування $[3,4]$. Оскільки різні форми аномальної плацентації можуть призвести до серйозних ускладнень, їх дородовій діагностиці приділяється надзвичайно велика увага.

Placenta acreta виникає, коли в децидуальній оболонці $€$ десрект, що дозволяє прив'язаним ворсинкам прилипати до міометрія. Частота аномальних плацентацій зросла в 10 разів за останні 20 років і зараз спостерігається у 9,3\% жінок із передлежанням плаценти або в 1 випадку на 533 пологів. Оперативне розродження $є$ найпоширенішою причиною децидуальних десектів і збільшення частоти аномальної плацентації. Цьому сприяє надмірно висока оперативна активність акушерів - в окремих країнах кожні другі пологи завершуються кесаревим розтином. Втім, ризик аномальної плацентації збільшується $324 \%$ при одноразовому кесаревому розтині до $67 \%$ при 4 кесаревих розродженнях. Іншими фракторами ризику для аномальної плацентації є субсерозна міома матки, попередня міомектомія, синдром Ашермана, вік матері понад 35 років, куріння та підвищений рівень $\alpha$-оретопротеїну. Для пренатальної діагностики аномальної плацентації застосовують ультразвукове дослідження, кольорову доплерометрію та магнітно-резонансну томографрію [5-16]. Втім, досі бракує якісних клініко-епідеміологічних досліджень поширеності аномальної плацентації у вагітних із рубцем.

МЕТА ДОСЛІДЖЕННЯ - оцінка частоти аномальної плацентації у вагітних із рубцем на матці.

МАТЕРІАЛИ ТА МЕТОДИ. Дослідження виконано на базі Одеського обласного перинатального центру впродовж 2016-2020 рр. Обстежено 435 жінок із рубцем на матці, в тому числі 118 (27,1 \%) - із двома та більше рубцями. Середній вік обстежених склав $(33,3 \pm 1,2)$ року.

Аналізували частоту виявлення аномалій плацентації на пренатальному етапі.

Всім пацієнткам під час вагітності у терміні 20 тижнів було проведено трансвагінальне ультразвукове дослідження за допомогою сканера експертного класу Accuvix V20 Prestige (Samsung Medison, Республіка Корея). Додатково проводили доплерометричне дослідження кровотоку по маткових артеріях.

Статистичний аналіз проводили з використанням програмного забезпечення Statistica 13.0 (TIBCO, США).

РЕЗУЛЬТАТИ ДОСЛІДЖЕННЯ ТА ЇХ ОБГОВОРЕННЯ. При аналізі акушерського анамнезу в обстежених вагітних визначено, що у всіх із часу виконання кесаревого розтину, міомектомії або метропластики минуло більше 2 років. Рубець після консервативної міомектомії був у 109 (25,1 \%) жінок. Середній термін після виконання КМЕ склав $(2,7 \pm 0,2)$ року. На відміну від жінок після КР, у яких розріз завжди локалізувався у нижньому сегменті матки, у пацієнток із рубцем на матці після КМЕ його локалізація відповідала первинній локалізації видаленого міоматозного вузла. Найбільш часто реєстрували фундальні (28, або 25,7 \%) та корпоральні (73, або 66,9 \%) розрізи.

Частим явищем були аномалії прикріплення плаценти -у 70,3 \%, причому в структурі ураження переважало низьке розташування плаценти - 163 випадки, або 53,3\%. Placenta accrete зареєстрована у 131, або 42,8 \%. Казу- їстикою були випадки placenta increta (2,6 \%) та placenta previa (1,3\%).

При оцінці частоти ускладнень у жінок із рубцем на матці встановлено, що у першому триместрі вагітності загроза переривання вагітності виникала у 20,4 \% вагітних, ранній гестоз - у 50,3 \%, анемія вагітних - у 64,1\%. Затримку росту плода реєстрували у 69,6 \% вагітних. У третьому триместрі прояви диссрункції плаценти реєстрували у 72,1 \%, прееклампсії - у 66,8 \%, анемії вагітних - у 73,6 \%. За літературними даними, поширеність аналогічних ускладнень у жінок без носійства рубця $€$ втричі меншою.

У 103 (25,9 \%) жінок вдавалися до оперативного розродження, в решти пологи відбулися per via naturales. Причинами виконання КР були аномалії розташування плаценти (по передній стінці, в ділянці рубця), Уз ознаки неспроможності рубця на матці (товщина, ехогенність, структура), а також ранні порушення гемодинамічних показників внутрішньоплацентарного кровотоку, що $€$ відображенням високого перинатального ризику.

Точна пренатальна діагностика аномалії плацентації дозволяє здійснювати відповідне консультування та обрати тактику розродження, що має суттєво знизити захворюваність та смертність. На сьогодні найбільш значущими вислідами аномальної плацентації $€$ масивні кровотечі й питання органозбереження, оскільки гістеректомія залишається основною лікувальною процедурою при placenta increta, яка дозволяє врятувати життя жінки.

Пренатальна діагностика placenta increta значною мірою орієнтована на ситуацію, коли хоріон здійснює інвазію в рубець після попереднього кесаревого розтину або міомектомії. На нашу думку, необхідно оцінювати плацентарний та міометральний кровотік у пацієнтів, які мають в анамнезі шрами в матці, пов'язані з іншими процедурами, ніж кесарів розтин.

У даний час жодний метод діагностики не встановлює діагнозу placenta accrete \& increta з абсолютною точністю; однак сонографрія залишається основним діагностичним інструментом. Чутливість та специсічність для цього методу дорівнює, відповідно, 82-93 та 79-96 \%.

Магнітно-резонансна томографрія може бути корисною у складних ситуаціях або при розташуванні плаценти по задній стінці. Залишається предметом дискусії можливість застосування у вагітних внутрішньовенного контрастування 3 гадолінієм, адже експериментальні дослідження свідчать про можливість його кумуляції у системі «мати - плід» [6, 17-20].

Слід зазначити, що морфофункціональний стан плаценти у вагітних із міомою матки залежить від особливостей міоматозних вузлів і їх розташування. Проліферуюча міома матки, великі розміри міоматозного вузла ( $\geq 5$ см), низька локалізація вузла (шийко-перешийкова), наявність множинних міоматозних вузлів матки, прикріплення плаценти в проекції міоматозного вузла $€$ основними фракторами ризику розвитку дисфункції плаценти у вагітних із міомою матки. Чим більша маса міоми, тим сильніше виражені ознаки патологічної трансорормації матки, тим вираженішими виявляються патогенетичні передумови для ускладненого перебігу вагітності та пологів. Це стосується й placenta accrete \& increta - наслідків аномальної імплантації в децидуальну 
оболонку або в міометрій, з якою пов'язують близько 7 \% смертності серед породілей.

ВИСНОВКИ. 1. Найчастішою причиною утворення рубця на матці є КР (74,9 \%). Рубець після консервативної міомектомії був у 109 (25,1\%) жінок.

2. Середній термін після виконання КМЕ склав $(2,7 \pm 0,2)$ року.

3. На відміну від жінок після КР, у яких розріз завжди локалізувався у нижньому сегменті матки, у пацієнток із рубцем на матці після КМЕ його локалізація відповідала первинній локалізації видаленого міоматозного вузла.
Найбільш часто реєстрували фрундальні (28, або 25,7 \%) та корпоральні $(73$, або 66,9 \%) розрізи.

4. Частим явищем були аномалії прикріплення плаценти - у 70,3 \% жінок, причому в структурі ураження переважало низьке розташування плаценти - 163 (53,3\%).

5. Placenta accrete зареєстрована у 42,8 \% вагітних, placenta increta - y 2,6 \% та placenta previa - y 1,3\%.

ПЕРСПЕКТИВИ ПОДАЛЬШИХ ДОСЛІДЖЕНЬ МОжуть бути пов'язані з розробкою систем антенатальної діагностики аномалій прикріплення плаценти у вагітних із рубцем на матці.

\section{СПИСОК ЛІТЕРАТУРИ}

1. Outcome of Cesarean scar pregnancy managed expectantly: systematic review and meta-analysis / G. Calì, I. E. Timor-Tritsch, J. Palacios-Jaraquemada [et al.] // Ultrasound Obstet. Gynecol. - 2018. - Vol. 51 (2). - P. 169-175.

2. Risk scoring system with MRI for intraoperative massive hemorrhage in placenta previa and accrete / D. Chen, J. Xu, P. Ye [et al.] // J. Magn. Reson Imaging. - 2020. - Vol. 51 (3). - P. 947-958.

3. Gonzalez N. Cesarean scar pregnancy: a systematic review / N. Gonzalez, T. Tulandi // J. Minim. Invasive Gynecol. - 2017. - Vol. 24 (5). - P. 731-738.

4. Jauniaux E. Pathophysiology of placenta accreta spectrum disorders: a review of current findings / E. Jauniaux, G. J. Burton // Clin. Obstet. Gynecol. - 2018. - Vol. 61 (4). - P. 743-754.

5. Jauniaux E. Placenta accreta spectrum: pathophysiology and evidence-based anatomy for prenatal ultrasound imaging / E. Jauniaux, S. Collins, G. J. Burton // Am. J. Obstet. Gynecol. - 2018. - Vol. 218 (1). - P. 75-87.

6. Lum M. MRI safety considerations during pregnancy / M. Lum, A. Tsiouris // J. Clin. Imaging. - 2020. - Vol. 62. - P. 69-75.

7. Retrospective multicenter study of leaving the placenta in situ for patients with placenta previa on a cesarean scar / K. Miyakoshi, T. Otani, E. Kondoh [et al.] // Int. J. Gynaecol. Obstet. - 2018. - Vol. 140 (3). - P. 345-351.

8. Zhelezov D. Periconceptional remodeling of myometrium after surgical interventions on the uterus: ultrasonographic aspects / D. Zhelezov // Georgian Med. News. - 2019. № 297. - P. 31-34.

9. Cesarean scar pregnancy complicated with placenta percreta / J. Fatusic, I. Hudic, A. Zildzic-Moralic, B. Hadziefendic // Med. Arch. - 2019. - Vol. 73 (1). - P. 58-60.

10. Special Report of the Society for Maternal-Fetal Medicine Placenta Accreta Spectrum Ultrasound Marker Task Force: Consensus on definition of markers and approach to the ultrasound examination in pregnancies at risk for placenta accreta spectrum / S. A. Shainker, B. Coleman, I. E. Timor-

\section{REFERENCES}

1. Cali, G., Timor-Tritsch, I.E., Palacios-Jaraquemada, J., Monteaugudo, A., Buca, D., Forlani, F., ..., \& D'Antonio, F. (2018). Outcome of Cesarean scar pregnancy managed expectantly: systematic review and meta-analysis. Ultrasound Obstet. Gynecol., 51 (2), 169-175. DOI: 10.1002/uog.17568.

2. Chen, D., Xu, J., Ye, P., Li, M., Duan, X., Zhao, F., ..., \& Peng, B. (2020). Risk scoring system with MRI for intraoperative
Tritsch [et al.] // Am. J. Obstet. Gynecol. - 2021. - Vol. 224 (1). - P. B2-B14.

11. Silver R. M. Placenta accreta spectrum: accreta, increta, and percreta / R. M. Silver, K. D. Barbour // Obstet. Gynecol. Clin. North Am. - 2015. - Vol. 42 (2). - P. 381-402.

12. Placenta accreta spectrum / A. G. Cahill, R. Beigi, R. P. Heine [et al.] // Am. J. Obstet. Gynecol. - 2018. - Vol. 219 (6). - P. B2-B16.

13. Placenta accreta spectrum: a review of pathology, molecular biology, and biomarkers / H. C. Bartels, J. D. Postle, P. Downey, D. J. Brennan // Dis. Markers. - 2018. - Vol. 2018. $-1507674$.

14. Dashraath P. Placenta Increta / P. Dashraath, H. Z. Lin // N. Engl. J. Med. - 2016. - Vol. 375 (14). - P. 1382.

15. Minimizing surgical blood loss at cesarean hysterectomy for placenta previa with evidence of placenta increta or placenta percreta: the state of play in 2020 / J. C. Kingdom, S. R. Hobson, A. Murji [et al.] // Am. J. Obstet. Gynecol. - 2020. - Vol. 223 (3). - P. 322-329.

16. Di Mascio D. Updates on the management of placenta accreta spectrum / D. Di Mascio, G. Calì, F. D'antonio // Minerva Ginecol. - 2019. - Vol. 71 (2). - P. 113-120.

17. Berkley E. M. Imaging of placenta accreta spectrum / E. M. Berkley, A. Abuhamad // Clin. Obstet. Gynecol. - 2018. Vol. 61 (4). - P. 755-765.

18. MRI of placenta accreta, placenta increta, and placenta percreta: pearls and pitfalls / A. Kilcoyne, A. S. Shenoy-Bhangle, D. J. Roberts [et al.] // AJR. Am. J. Roentgenol. - 2017. Vol. 208 (1). - P. 214-221.

19. New evidence-based diagnostic and management strategies for placenta accreta spectrum disorders / E. Jauniaux, A. M. Hussein, K. A. Fox, S. L. Collins // Best Pract. Res. Clin. Obstet. Gynaecol. - 2019. - Vol. 61. - P. 75-88.

20. MRI of placenta percreta: differentiation from other entities of placental adhesive disorder / S. Thiravit, S. Lapatikarn, K. Muangsomboon [et al.] // Radiol. Med. - 2017. - Vol. 122 (1). - P. 61-68.

massive hemorrhage in placenta previa and accreta. J. Magn. Reson Imaging., 51 (3), 947-958. DOI: 10.1002/jmri.26922.

3. Gonzalez, N., \& Tulandi, T. (2017). Cesarean scar pregnancy: a systematic review. J. Minim. Invasive Gynecol., 24 (5), 731-738. DOI: 10.1016/j.jmig.2017.02.020.

4. Jauniaux, E., \& Burton, G.J. (2018). Pathophysiology of placenta accreta spectrum disorders: a review of current find- 
ings. Clin. Obstet. Gynecol., 61 (4), 743-754. DOI: 10.1097/ GRF.0000000000000392.

5. Jauniaux, E., Collins, S., \& Burton, G.J. (2018). Placenta accreta spectrum: pathophysiology and evidence-based anatomy for prenatal ultrasound imaging. Am. J. Obstet. Gynecol. 218 (1), 75-87. DOI: 10.1016/j.ajog.2017.05.067.

6. Lum, M., \& Tsiouris, A. (2020). MRI safety considerations during pregnancy. J. Clin. Imaging., 62, 69-75. DOI: 10.1016/j. clinimag.2020.02.007.

7. Miyakoshi, K., Otani, T., Kondoh, E., Makino, S., Tanaka, M., \& Takeda, S. (2018). Retrospective multicenter study of leaving the placenta in situ for patients with placenta previa on a cesarean scar. Int. J. Gynaecol. Obstet., 140 (3), 345-351. DOI: 10.1002/ijgo.12397.

8. Zhelezov, D. (2019). Periconceptional remodeling of myometrium after surgical interventions on the uterus: ultrasonographic aspects. Georgian Med News., 297, 31-34.

9. Fatusic, J., Hudic, I., Zildzic-Moralic, A., \& Hadziefendic, B. (2019). Cesarean scar pregnancy complicated with placenta percreta. Med. Arch., 73 (1), 58-60. DOI: 10.5455/ medarh.2019.73.58-60.

10. Shainker, S.A., Coleman, B., Timor-Tritsch, I.E., Bhide, A., Bromley, B., Cahill, A.G., ..., \&Abuhamad, A. (2021). Special Report of the Society for Maternal-Fetal Medicine Placenta Accreta Spectrum Ultrasound Marker Task Force: Consensus on definition of markers and approach to the ultrasound examination in pregnancies at risk for placenta accreta spectrum. Am. J. Obstet. Gynecol., 224 (1), B2-B14. DOI: 10.1016/j.ajog.2020.09.001.

11. Silver, R.M., \& Barbour, K.D. (2015). Placenta accreta spectrum: accreta, increta, and percreta. Obstet. Gynecol. Clin. North Am., 42 (2), 381-402. DOI: 10.1016/j.ogc.2015.01.014.

12. Cahill, A.G., Beigi, R., Heine, R.P., Silver, R.M., \&Wax, J.R. (2018). Placenta accreta spectrum. Am. J. Obstet. Gynecol., 219 (6), B2-B16. DOI: 10.1056/NEJMcp1709324.
13. Bartels, H.C., Postle, J.D., Downey, P., \& Brennan, D.J. (2018). Placenta accreta spectrum: a review of pathology, molecular biology, and biomarkers. Dis. Markers., 2018, 1507674. DOI: $10.1155 / 2018 / 1507674$.

14. Dashraath, P., \& Lin, H.Z. (2016). Placenta increta. N. Engl. J. Med., 375 (14), 1382. DOI: 10.1056/NEJMicm1513423.

15. Kingdom, J.C., Hobson, S.R., Murji, A., Allen, L., Windrim, R.C., Lockhart, E., ..., \& Fox, K.A. (2020). Minimizing surgical blood loss at cesarean hysterectomy for placenta previa with evidence of placenta increta or placenta percreta: the state of play in 2020. Am. J. Obstet. Gynecol., 223 (3), 322-329. DOI: 10.1016/j.ajog.2020.01.044.

16. Di Mascio, D., Calì, G., \& D'antonio, F. (2019). Updates on the management of placenta accreta spectrum. Minerva Ginecol., 71 (2), 113-120. DOI: 10.23736/S0026-4784.18.04333-2.

17. Berkley, E.M., \& Abuhamad, A. (2018). Imaging of placenta accreta spectrum. Clin. Obstet. Gynecol., 61 (4), 755-765. DOI: $10.1097 / G R F .0000000000000407$.

18. Kilcoyne, A., Shenoy-Bhangle, A.S., Roberts, D.J., Sisodia, R.C., Gervais, D.A., \& Lee, S.I. (2017). MRI of placenta accreta, placenta increta, and placenta percreta: pearls and pitfalls. AJR. Am. J. Roentgenol., 208 (1), 214-221. DOI: $10.2214 / A J R .16 .16281$

19. Jauniaux, E., Hussein, A.M., Fox, K.A., \& Collins, S.L. (2019). New evidence-based diagnostic and management strategies for placenta accreta spectrum disorders. Best Pract. Res. Clin. Obstet. Gynaecol., 61, 75-88. DOI: 10.1016/j. bpobgyn.2019.04.006.

20. Thiravit, S., Lapatikarn, S., Muangsomboon, K., Suvannarerg, V., Thiravit, P., \& Korpraphong, P. (2017). MRI of placenta percreta: differentiation from other entities of placental adhesive disorder. Radiol. Med., 122 (1), 61-68. DOI: 10.1007/ s11547-016-0689-3.

Отримано 02.04.2021

Прийнято до друку 04.05.2021 Електронна адреса для листування: zhelezoff@i.ua 